\title{
Adjuvant chemotherapy in stage I lung cancer: Is more better?
}

\author{
Chuong D. Hoang, MD
}

\footnotetext{
From the Section of Thoracic Surgery, National Cancer Institute-National Institutes of Health, Center for Cancer Research, and The Clinical Center, Bethesda, Md.

Disclosures: Author has nothing to disclose with regard to commercial support.

Received for publication June 26, 2018; revisions received June 26, 2018; accepted for publication June 27, 2018; available ahead of print Aug 11, 2018.

Address for reprints: Chuong D. Hoang, MD, Section of Thoracic Surgery, National Cancer Institute-National Institutes of Health, Center for Cancer Research, and The Clinical Center, 10 Center Dr, Mail Code 1201, Room 4-3940, Bethesda, MD 20892 (E-mail: chuong.hoang@nih.gov).

J Thorac Cardiovasc Surg 2018;156:2016-7

0022-5223/\$0.00

Published by Elsevier Inc. on behalf of The American Association for Thoracic Surgery https://doi.org/10.1016/j.jtcvs.2018.06.069
}

With the new eighth edition TNM staging system for non-small cell lung cancer (NSCLC), there is better stratification, particularly in early stages, based on objective analyses revealing distinct survival differences according to tumor size in increments of $1 \mathrm{~cm}$ (up to $5 \mathrm{~cm}$ ). Now, an opportunity exists to re-examine standard-of-care practices for NSCLC based on new definitions of TNM stage.

Despite resection of NSCLC, the 5-year overall survival (OS) varies from $90 \%$ in patients with pathologic stage IA 1 to $41 \%$ in those with stage IIIA. ${ }^{1}$ The majority of patients with NSCLC are offered adjuvant chemotherapy based on phase III trials (reported between 2003 and 2006) that, when meta-analyzed in $2008,{ }^{2}$ demonstrated survival benefit for patients with stage II to IIIA disease and a likely detrimental effect in patients with stage IA disease.

The clinical approach to stage IB disease remains controversial because of confounding results. The mature reporting of Cancer and Leukemia Group B $9633,{ }^{3}$ the only randomized trial specifically investigating adjuvant chemotherapy in patients with stage IB disease, indicated no OS benefit. However, an updated meta-analysis of more than 4500 patients pooled from 16 trials with resected stage IB disease showed that adjuvant chemotherapy associated with a significant OS improvement (hazard ratio, $0.74 ; 95 \%$ confidence interval, $0.63-0.88 ; P<.001){ }^{4}$ The benefit was realized mostly in those patients receiving uracil and tegafur (not approved for use in the United States), whereas there was no benefit associated with platinum-based chemotherapy. Lastly, a recent multivariate analysis of the National Cancer Data Base (20042011) revealed improved median and 5-year OS in patients with resected NSCLC tumors 3.1 to $3.9 \mathrm{~cm}$ in size, among other sizes comprising T2 (seventh edition TNM), who received adjuvant chemotherapy (hazard ratio, $0.77 ; 95 \%$ confidence interval, $0.70-0.83 ; P<.001)$. in this area.

\section{References} 11:39-51.

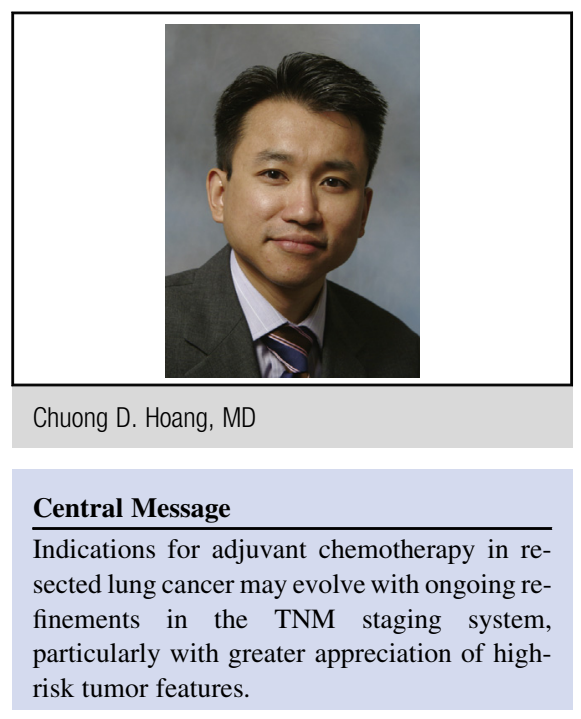

See Article page 2006.

Following this modern trend suggesting that adjuvant chemotherapy may be beneficial in smaller NSCLC tumors, Wang and colleagues ${ }^{6}$ explore the intriguing notion of adjuvant chemotherapy in the subgroup of resected NSCLC patients with stage IA 1 to IA 3 and IB disease stratified by lymphovascular invasion status of the primary tumor. Their unique multidisciplinary, locoregional practice allowed adjuvant chemotherapy in patients with stage I disease, contrary to guidelines established earlier. ${ }^{2}$ Certainly, the improved recurrence-free survival and OS rates in all stage I subgroups with lymphovascular invasion, as reported here, will inspire other, similar investigations. Thus, Wang and colleagues ${ }^{6}$ reopen the discussion on indications for adjuvant chemotherapy in resected NSCLC as well as inform about the design options of prospective trials

1. Goldstraw P, Chansky K, Crowley J, Rami-Porta R, Asamura H, Eberhardt WE, et al. The IASLC Lung Cancer Staging Project: proposals for revision of the TNM stage groupings in the forthcoming (eighth) edition of the TNM Classification for Lung Cancer. J Thorac Oncol. 2016;

2. Pignon JP, Tribodet H, Scagliotti GV, Douillard JY, Shepherd FA, Stephens RJ, et al. Lung adjuvant cisplatin evaluation: a pooled analysis by the LACE Collaborative Group. J Clin Oncol. 2008;26:3552-9.

3. Strauss GM, Herndon JE II, Maddaus MA, Johnstone DW, Johnson EA, Harpole DH, et al. Adjuvant paclitaxel plus carboplatin compared with observation in stage IB non-small-cell lung cancer: CALGB 9633 with the 
Cancer and Leukemia Group B, Radiation Therapy Oncology Group, and North Central Cancer Treatment Group Study Groups. J Clin Oncol. 2008; 26:5043-51.

4. He J, Shen J, Yang C, Jiang L, Liang W, Shi X, et al. Adjuvant chemotherapy for the completely resected stage IB nonsmall cell lung cancer: a systematic review and meta-analysis. Medicine. 2015;94:e903.
5. Morgensztern D, Du L, Waqar SN, Patel A, Samson P, Devarakonda S, et al. Adjuvant chemotherapy for patients with T2N0M0 NSCLC. J Thorac Oncol. 2016;11: 1729-35.

6. Wang S, Xu J, Wang R, Qian F, Yang W, Qiao R, et al. Adjuvant chemotherapy may improve prognosis after resection of stage I lung cancer with lymphovascular invasion. J Thorac Cardiovasc Surg. 2018;156:2006-15. 